\title{
Evaluación de la unión espermatozoide-ADN exógeno en espermatozoides porcinos eyaculados y epididimarios ${ }^{\#}$
}

\author{
Evaluation of binding sperm-exogenous DNA in ejaculate and epididimary \\ porcine spermatozoa \\ FA García-Vázquez ${ }^{a}$, A Gutiérrez-Adán ${ }^{\text {b }}$, Gadea ${ }^{a}$ \\ aDepartamento de Fisiología, Facultad de Veterinaria, Universidad de Murcia, Murcia, España. \\ bepartamento de Reproducción Animal, INIA, Madrid, España.
}

\begin{abstract}
SUMMARY
Transgenic biotechnology is a powerful tool for the generation of genetically modified animals with applications in various fields such as veterinary, agriculture and biomedicine. Sperm mediated gene transfer (SMGT) is an interesting tool for animal transgenesis consisting on the intrinsic ability of the spermatic cells to bind and internalize exogenous DNA and allow their transfer into oocytes after fertilization, to become part of the genome of the new embryo. The seminal plasma plays an important role acting as a natural barrier and protecting the spermatozoa from exogenous molecules that could compromise their integrity. So, the epididymal spermatozoa are a valuable model to explore the possible effect of seminal plasma components. The objective of this study was to evaluate the interaction among sperm and transgene using Epididymal (EP) vs Ejaculated (EJ) sperm without seminal plasma. Linealized plasmid (GFP) $(5.7 \mathrm{~kb})$ labelled with fluorescein was added $\left(1 \times 10^{8}\right.$ spermatozoa $/ \mathrm{ml}+5 \mu \mathrm{g}$ DNA/ml $)$ and incubated at $16^{\circ} \mathrm{C}$. DNA binding and viability were measured simultaneously by flow cytometry during 120 minutes of incubation. The results showed that EP spermatozoa present a similar DNA-binding ability $(12.63 \pm 1.23 \%$ vs $10.94 \pm 1.05 \%, \mathrm{P}=0.31)$ and viability throughout the incubation $(14.64 \pm 0.94 \%$ vs $13.42 \pm 0.61 \%$, $\mathrm{P}=0.23)$ than EJ. We only detected a greater percentage of living DNA-bound spermatozoa in EP compared to EJ $(2.10 \pm 0.33 \%$ vs $1.05 \pm 0.14 \%$, $\mathrm{P}<0.01$ ). The DNA-binding was associated mainly to dead sperm or with low viability in both groups (EP: $10.53 \pm 1.01 \% \mathrm{vs}$ EJ: $9.89 \pm 0.97 \%$, $\mathrm{P}=0.98$ ). These results open new ways to explore and use epididymal spermatozoa in diverse applications (artificial insemination, in vitro fertilization and ICSI) associated with SMGT method.
\end{abstract}

Palabras clave: espermatozoides, ADN exógeno, transgénesis, porcino.

Key words: spermatozoa, SMGT, transgenesis, porcine.

\section{INTRODUCCIÓN}

La producción de organismos transgénicos ha sido el mayor avance en el ámbito de la biología en los últimos tiempos, siendo providencial en el estudio de mecanismos genéticos de regulación y desarrollo biológico. Se han producido numerosas mejoras en la tecnología de la transgénesis desde su inicio allá por el año 1981 (Gordon y Ruddle 1981), y son varios los sistemas de transferencia de ADN que se realizan hoy en día con una gran eficiencia y con unos costos reducidos. Desde hace casi dos décadas el uso de los espermatozoides como vectores de ADN exógeno (Sperm Mediated Gene Transfer: SMGT) ha centrado la atención de numerosos investigadores en un continuo debate sobre la transgénesis animal. En 1989 se publicó un trabajo donde se demostraba la capacidad que tenían los espermatozoides de transportar ADN exógeno y transferir estas moléculas mediante fecundación dando

Aceptado: 19.11.2008.

\# Proyectos BIOCARM 10BIO2005/01-6463 y MEC-FEDER AGL200603495.

* Departamento de Fisiología, Facultad de Veterinaria, Universidad de Murcia, 30100, Murcia, España; fagarcia@um.es lugar a animales modificados genéticamente (Lavitrano y col 1989). Esto supuso un importante avance en el campo de la transgénesis, de manera que la SMGT podría ser considerada por su relativa sencillez y bajo costo como la técnica de elección para la producción de animales de granja modificados genéticamente y representaría una poderosa herramienta para la investigación en diversos campos de la medicina. Usando esta técnica se ha obtenido un porcentaje que se encuentra entre el 5 y el 80 de animales transgénicos del total de nacidos y la eficiencia varía según las especies de aplicación. Por tanto, dicho método mejora notablemente la eficiencia que se alcanza cuando se emplea la microinyección pronuclear que se encuentra entre 0,5-4\% (Niemann y Kues 2003).

Sin embargo, las dificultades en la repetitividad y la baja eficiencia en la integración de los transgenes en el genoma del animal resultaron en una considerable controversia sobre dicho trabajo durante numerosos años (Brinster y col 1989, Birnstiel y Busslinger 1989). No obstante, recientemente se han publicado numerosos estudios confirmando que los espermatozoides de múltiples especies pueden ser usados como vectores para introducir transgenes dentro del genoma del animal (Smith y Spadafora 2005). Entre los diferentes animales donde se ha aplicado esta técnica se encuentran el ratón (Lavitrano y col 1989, Hochi y col 1990, Bachiller 
y col 1991, Maione y col 1998, Sciamanna y col 2000, Sato y col 2002), conejo (Brackett y col 1971, Kuznetsov y Kuznetsov 1995, Wang y col 2001), cerdo (Sperandio y col 1996, Gandolfi y col 1998, Lavitrano y col 2002, Nagashima y col 2003), pollo (Fainsold y col 1990, Yang y col 2004), rana (Xenopus laevis) (Kroll y Amaya 1996, Jonak 2000), vacuno (Pérez y col 1991, Sperandio y col 1996, Rieth y col 2000) y en algunas especies de peces (Sin y col 2000, Venugopal y col 2004).

El ADN exógeno interactúa con proteínas de 30-35 KDa, las cuales están presentes en la superficie de las células espermáticas (Lavitrano y col 1992, Zani y col 1995). No obstante, los espermatozoides maduros tienen una protección natural para evitar la intrusión de ADN foráneo. El plasma seminal antagoniza con la unión del ADN exógeno, ejerciendo una poderosa protección del espermatozoide. Un factor inhibidor denominado IF-1 fue detectado tanto en el plasma seminal como en la superficie del espermatozoide (Zani y col 1995). En ausencia de IF-1, las proteínas de unión son capaces de interaccionar con el ADN introduciéndolo en la célula espermática (Lavitrano y col 1997). Por lo tanto, este factor juega un papel importante actuando como una barrera natural y protegiendo el espermatozoide de intrusiones de moléculas exógenas que pudieran comprometer la integridad del espermatozoide y la identidad genética de la progenie (Spadafora 1998).

En este sentido, se han observado diferencias en la eficiencia del transporte de los espermatozoides de ADN exógeno y la generación de animales transgénicos. Así, en cerdos se ha logrado una alta eficiencia con esta técnica, obteniéndose, en algunos estudios, resultados que muestran que más del $80 \%$ de la descendencia eran transgénicos (Lavitrano y col 2002), mientras que el éxito fue más limitado en la producción de cabras transgénicas (Schellander y col 1995). Las causas de las diferencias entre laboratorios y entre especies no están todavía claras, y, en consecuencia, la SMGT, aun siendo una técnica muy prometedora, no ha sido del todo adoptada para la creación de animales transgénicos.

Los estudios en la especie porcina de SMGT se han realizado mayoritariamente con semen eyaculado refrigerado en las mismas condiciones que se hace en la producción porcina (Lavitrano y col 2002 y 2003) y en menor medida con semen eyaculado congelado (García-Vázquez 2007). Sin embargo, el uso de espermatozoides epididimarios porcinos no ha sido estudiado hasta el momento. Este tipo de espermatozoide puede ser un buen modelo para el estudio de la interacción con el ADN, ya que no ha estado en contacto con los componentes del plasma seminal que modulan el proceso de unión espermatozoide-ADN. Por tanto el objetivo principal de nuestro trabajo fue evaluar y comparar el grado de unión, viabilidad espermática y cinética de unión entre el ADN exógeno y espermatozoides mediante el uso del citómetro de flujo en eyaculados a los que se eliminó el plasma seminal y espermatozoides epididimarios.

\section{MATERIAL Y MÉTODOS}

\section{ANIMALES}

El semen utilizado de verracos de fertilidad probada pertenecientes al centro de inseminación artificial de la granja "Lo Navarro" S.A. (Murcia, España). Los animales estuvieron alojados en habitáculos individuales mantenidos a temperatura controlada $\left(25^{\circ} \mathrm{C}\right)$ y bajo condiciones naturales de luz y humedad. Los programas sanitarios y nutricionales, aplicados a los verracos, fueron los utilizados sistemáticamente en la granja.

\section{MEDIO UTILIZADO PARA EL PROCESADO ESPERMÁTICO}

El medio utilizado para la dilución y lavado de los espermatozoides fue el Swine Fertilisation Medium (SFM) descrito previamente por Lavitrano y col (2002). Este medio está compuesto por glucosa $(11,25 \mathrm{~g} / \mathrm{l})$, citrato sódico (10 g/l), EDTA (4,7 g/l), ácido cítrico (3,25 g/l), Trizma (6,5 g/l). Posteriormente fue suplementado con 6 $\mathrm{mg} / \mathrm{ml}$ de Albúmina Sérica Bovina (BSA) para inducir el proceso de capacitación temprano ya que según Lavitrano y col (2003) es el momento óptimo donde se produce la unión entre el espermatozoide y el ADN exógeno. $\mathrm{El} \mathrm{pH}$ final del medio fue ajustado a 6,8 .

\section{PLÁSMIDO EGFP}

El plásmido EGFP, que hemos utilizado en este trabajo, contiene el promotor temprano CMV (citomegalovirus) humano y fue obtenido de Clontech (pEGFP-N1, 5.7 Kpb, Clontech Laboratories, Inc., Palo Alto, CA, EE.UU.). El plásmido se hizo lineal mediante el uso de AflII. Finalmente el plásmido lineal fue marcado con fluoresceína-12-dUTP (Roche ${ }^{\circledR}$, Alemania). La incorporación del nucleótido marcado en el ADN sintetizado disminuye su movilidad electroforética con respecto al ADN no marcado (GutiérrezAdán y Pintado 2000).

\section{RECOGIDA DEL SEMEN Y PROCESADO DE ESPERMATOZOIDES}

Espermatozoides eyaculados. La recogida de semen se realizó mediante el método manual (King y Macpherson 1973). La primera fracción del eyaculado (concentración baja de espermatozoides) fue eliminada, y la fracción rica en espermatozoides fue recogida en un termo estéril precalentado a $37^{\circ} \mathrm{C}$ (para evitar el choque térmico) y filtrada mediante gasas estériles para descartar las secreciones de la glándula de Cowper. Inmediatamente tras la recolección del eyaculado, el semen fue diluido 1:1 en medio SFM sin BSA, precalentado a $37^{\circ} \mathrm{C}$.

El semen fue preparado por el método descrito por Lavitrano y col (2002). Tras la recogida de la fracción rica del eyaculado y la dilución del semen 1:1 en medio SFM sin BSA, fue trasladado al laboratorio en un termo 
eléctrico a $37^{\circ} \mathrm{C}$. Una vez en el laboratorio, se diluyó de nuevo en medio SFM $\left(37^{\circ} \mathrm{C}\right)$ en una proporción de 1:10 ( $5 \mathrm{ml}$ semen 1:1 $+45 \mathrm{ml}$ medio) en tubos Falcon ${ }^{\circledR}$, y se centrifugó a $800 \mathrm{~g}$ durante $10 \mathrm{~min}$ a $25^{\circ} \mathrm{C}$.

Seguidamente, se eliminó el sobrenadante y se resuspendió de nuevo en SFM (en este caso con BSA) a $25^{\circ} \mathrm{C}$, de nuevo se centrifugó a $800 \mathrm{~g}$ durante $10 \mathrm{~min}$ a $25^{\circ} \mathrm{C}$; se descartó el sobrenadante y se añadió $1 \mathrm{ml}$ del medio con BSA a $25^{\circ} \mathrm{C}$. Una vez acabado el procesado de los espermatozoides se valoró la motilidad mediante la observación en microscopio de campo claro con objetivo 10X, depositando $10 \mu \mathrm{l}$ de la muestra sobre un portaobjetos precalentado en una placa térmica atemperada a $38^{\circ} \mathrm{C}$. Se valoró el porcentaje de espermatozoides con movimiento (0-100) y el tipo de movimiento rectilíneo, progresivo y rápido en una escala de 0 a 5 (Gadea y col 1998). Para su uso en los experimentos debía alcanzar una motilidad superior al $65 \%$ y una motilidad progresiva no inferior a 2,5. Se calculó la concentración final mediante un sistema espectrofotométrico (SpermaCue ${ }^{\circledR}$, Minitub). Finalmente, se ajustó la concentración de la suspensión espermática a $10^{8}$ células espermáticas $/ \mathrm{ml}$, a los que se le añadieron $5 \mu \mathrm{g}$ del plásmido EGFP/ml (solución stock del plásmido EGFP $200 \mathrm{ng} / \mu \mathrm{l})$.

Espermatozoides de epidídimo. Los epidídimos utilizados procedían de verracos sanos sacrificados en matadero. El transporte al laboratorio se realizó en un recipiente isotermo en un plazo máximo de $1 \mathrm{~h}$ tras el sacrificio. Una vez en el laboratorio, los testículos y los epidídimos fueron lavados con solución salina atemperada procediéndose tras ello a la disección de la cola del epidídimo. Posteriormente se lavó el conducto con $2 \mathrm{ml}$ de medio BTS (Bestwille Thawing Solution) utilizando una aguja de $21 \mathrm{G}$ acoplada a una jeringuilla de $5 \mathrm{ml}$. Las muestras resultantes del lavado fueron analizadas y solamente se utilizaron aquellas en las que la población espermática mantenía su integridad de membrana en un número superior al $80 \%$. La integridad de membrana se valoró incubando los espermatozoides en una solución que contenía $20 \mu \mathrm{l}$ de la solución stock de diacetato de carboxifluoresceína (DCF) $[0,46 \mathrm{mg} / \mathrm{ml}$ DCF en dimetil-sulfóxido (DMSO)], a la cual se le añadieron $20 \mu \mathrm{l}$ de solución de ioduro de propidio (IP) [IP en solución salina fisiológica (SSF) $500 \mu \mathrm{g} / \mathrm{ml}], 10 \mu \mathrm{de}$ SS formolada, $100 \mu \mathrm{l}$ de la muestra de semen y $900 \mu \mathrm{l}$ de SSF (Harrison y Vickers 1990). Esta suspensión se incubó a temperatura ambiente durante $10 \mathrm{~min}$ en un lugar protegido de la luz. Pasado este tiempo se colocaron $10 \mu \mathrm{l}$ de la solución final en un portaobjetos y bajo un cubreobjetos. Finalmente, se valoró mediante microscopia de fluorescencia (Leica ${ }^{\circledR}$ modelo DMLS) con un filtro de excitación a $580 \mathrm{~nm}$ bajo objetivo de inmersión (100X). Clasificamos los espermatozoides observados en dos grupos: 1) Células con fluorescencia verde: Integridad de membrana intacta; 2) Células con fluorescencia roja: Integridad de membrana alterada.
Los espermatozoides epididimarios fueron resuspendidos en medio SFM y centrifugados a $800 \mathrm{~g}$ durante $10 \mathrm{~min}$ a $25^{\circ} \mathrm{C}$; posteriormente tras descartar el sobrenadante se resuspendió en SFM pero en este caso con BSA, centrifugando de nuevo en las mismas condiciones anteriormente descritas. Se descartó el sobrenadante y se añadió $1 \mathrm{ml}$ de SFM con BSA a $25^{\circ} \mathrm{C}$. Se calculó la concentración final mediante el sistema espectrofotométrico $\left(\right.$ SpermaCue $^{\circledR}$, Minitub). Finalmente, se ajustó la concentración de la suspensión espermática a $10^{8}$ células espermáticas $/ \mathrm{ml}$ a los que se le añadieron $5 \mu \mathrm{g}$ del plásmido $\mathrm{EGFP} / \mathrm{ml}$ (solución stock del plásmido EGFP $200 \mathrm{ng} / \mu \mathrm{l}$ ).

\section{EVALUACIÓN DE LA UNIÓN ESPERMATOZOIDE-ADN Y VIABILIDAD ESPERMÁTICA MEDIANTE CITOMETRÍA DE FLUJO}

El análisis de la unión espermatozoide-ADN y viabilidad espermática fue realizado mediante un citómetro Coulter Epics XL (Beckman Coulter Inc., Miami, Florida. USA). Los datos medidos por el citómetro fueron analizados usando el programa Expo32ADC (Beckman Coulter Inc.).

Inicialmente se hizo una selección primaria basada en el tamaño y complejidad de la superficie celular para excluir partículas contaminantes, aglutinaciones, células somáticas, etc. De esta manera se seleccionaron sólo las partículas con un tamaño y complejidad de la superficie compatible con las células espermáticas. La intensidad de fluorescencia que presentaban los espermatozoides fue analizada mediante el registro de fluorescencia verde (FL1), recogido a través de un filtro de $525 \mathrm{~nm}$, mientras que el registro de fluorescencia roja (FL3) se realizó a través de un filtro de $575 \mathrm{~nm}$.

Para realizar diversos estudios de la unión al ADN y simultáneamente la evaluación de la viabilidad celular fue necesario el empleo de dos fluorocromos. Los espermatozoides fueron incubados con EGFP marcado con fluoresceína y al mismo tiempo con ioduro de propidio (9.6 $\mu \mathrm{l} \mathrm{IP} \mathrm{de} \mathrm{la} \mathrm{solución} \mathrm{stock} 500 \mu \mathrm{g} / \mathrm{ml}$, por cada $\mathrm{ml} \mathrm{de}$ muestra), y posteriormente medidos en el citómetro de la manera antes descrita. Al utilizar conjuntamente dos fluorocromos es posible distinguir cuatro subpoblaciones que describimos a continuación: 1) Espermatozoides vivos sin ADN unido (Ningún signo de fluorescencia), 2) Espermatozoides vivos con ADN unido (Únicamente fluorescencia verde), 3) Espermatozoides muertos con ADN unido (Fluorescencia verde y roja), 4) Espermatozoides muertos sin ADN unido (Fluorescencia roja).

\section{DISEÑO EXPERIMENTAL}

Para esta experiencia se utilizaron espermatozoides epididimarios y espermatozoides eyaculados sin plasma seminal. Los espermatozoides de ambos grupos fueron coincubados con el transgén EGFP $(5 \mu \mathrm{g}$ de ADN exógeno/ml) marcado con fluoresceína en la relación 
$10^{8}$ células espermáticas $/ \mathrm{ml}$, y mantenidos a $16^{\circ} \mathrm{C}$ durante la incubación y el análisis. A su vez, se valoró la viabilidad espermática mediante la tinción con IP. Se analizaron, mediante el citómetro de flujo, 10.000 células espermáticas por grupo y tres mediciones por muestra a lo largo del tiempo de incubación $(0,15,30,60,90$ y $120 \mathrm{~min}$ ), a una velocidad de 500 células/segundo. Para cada medición se tomaron $100 \mu$ de muestra a los que se le añadieron $3 \mathrm{ml}$ de PBS (Phosphate Buffer Saline). Se realizó un total de tres replicados para esta experiencia.

\section{ANÁLISIS ESTADÍSTICO}

Se muestran los valores medios y el error estándar de la media de los parámetros estudiados. Se realizó un estudio de ANOVA considerando como efectos fijos el tipo de espermatozoide empleado (eyaculado vs epididimario) y el tiempo de incubación (0, 15, 30, 60, 90 y $120 \mathrm{~min})$. Se consideraron diferencias significativas cuando $\mathrm{P}<0,05$. Se utilizó el programa Systat v11 (Systat Software Inc., 2004, Richmond, CA 94804, USA).

\section{RESULTADOS}

Cuando analizamos la cinética de la unión del ADN a los espermatozoides (cuadro 1 y figura 1) observamos que tanto para espermatozoides eyaculados como epididimarios el mayor porcentaje de unión con el transgén (referida la unión del ADN tanto a espermatozoides vivos como muertos) ocurre en los primeros $15 \mathrm{~min}$ de coincubación (Eyaculado: 13,07 \pm 1,42\% vs Epidídimo: $15,53 \pm 3,24 \% ; \mathrm{P}=0,43)$, a partir del cual la unión se mantiene más o menos constante hasta los $120 \mathrm{~min}$ (Eyaculado: $13,17 \pm 0,27 \%$ vs Epididimario: $13,20 \pm 2,15 \% ; \mathrm{P}=0,85$ ), manteniendo un patrón de unión similar para ambos grupos. Del mismo modo, la unión del ADN a células viables se produce de manera rápida en ambos tipos de espermatozoides, aunque durante los primeros $30 \mathrm{~min}$ de incubación el porcentaje de unión es significativamente superior en los espermatozoides epididimarios (en los primeros 15 min de incubación: Eyaculado: 1,70 \pm 0,39\% vs Epididimario: 4,35 $\pm 1,65 \%, \mathrm{P}=0,09$; a los 30 min de incubación: Eyaculado: 1,38 $\pm 0,27 \%$ vs. Epididimario: $3,03 \pm 0,42 \%, \mathrm{P}<0,01)$, llegando a los 120 min con unos porcentajes de unión similares en ambos grupos (Eyaculado: $1,43 \pm 0,09 \%$ vs Epididimario: 1,32 $\pm 0,43 \%, \mathrm{P}=0,85)$ (cuadro 1 y figura 2).

En el cuadro 2 se representan los valores medios teniendo en cuenta las mediciones realizadas en los diferentes tiempos de incubación (es decir, la media de los valores medidos a los 0, 15, 30, 60, 90 y 120 min). Los espermatozoides epididimarios presentan una capacidad similar a los eyaculados y centrifugados tanto en el grado de unión al $\operatorname{ADN}(12,63 \pm 1,23 \%$ vs $10,94 \pm 1,05 \%, P=0,31)$ como en la viabilidad espermática (espermatozoides no viables $14,64 \pm 0,94 \%$ vs $13,42 \pm 0,61 \%, \mathrm{P}=0,23)$ a lo largo del tiempo de incubación (cuadro 2). La mayor parte de dicha unión tiene lugar en los espermatozoides no viables para ambos tipos de espermatozoides $(10,53 \pm 1,01 \%$ vs

Cuadro 1. Datos de \% de unión (unión total, unión a espermatozoides muertos y unión a espermatozoides vivos) y viabilidad a lo largo de 120 min de incubación $(0,15,30,60,90,120 \mathrm{~min})$ para espermatozoides epididimarios y eyaculados sin plasma seminal.

Values for DNA binding \% (total binding, binding to live and dead spermatozoa) and viability of epididymal and ejaculated spermatozoa measured at different times $(0,15,30,60,90,120 \mathrm{~min})$ during $120 \mathrm{~min}$ of incubation.

\begin{tabular}{|c|c|c|c|c|c|c|c|c|}
\hline & $\begin{array}{c}\text { Tipo } \\
\text { espermatozoide }\end{array}$ & & & $\begin{array}{l}\text { Tiempo } \\
\text { (min) }\end{array}$ & & & & $\mathrm{P}$ \\
\hline & & 0 & 15 & 30 & 60 & 90 & 120 & \\
\hline \multirow{2}{*}{$\begin{array}{l}\% \text { Espz } \\
\text { muertos }\end{array}$} & Eyaculado & $8,90 \pm 1,32^{\mathrm{a}}$ & $14,08 \pm 1,50^{\mathrm{b}}$ & $14,22 \pm 1,46^{\mathrm{b}}$ & $12,28 \pm 0,45^{\mathrm{b}}$ & $15,93 \pm 1,03^{b}$ & $13,43 \pm 0,27^{b}$ & $P=0,02$ \\
\hline & Epididimario & $9,38 \pm 1,76$ & $16,60 \pm 2,97$ & $16,10 \pm 1,47$ & $15,94 \pm 2.96$ & $14,83 \pm 2,21$ & $13,98 \pm 2,08$ & $\mathrm{P}=0,35$ \\
\hline $\mathrm{P}$ & & 0,84 & 0,43 & 0,38 & 0,26 & 0,66 & 0,85 & \\
\hline \multirow{2}{*}{ \% Unión total } & Eyaculado & $0^{\mathrm{a}}$ & $13,07 \pm 1,42^{\mathrm{b}}$ & $13,10 \pm 1,46^{\mathrm{b}}$ & $11,94 \pm 0,62^{b}$ & $15,65 \pm 1,07^{b}$ & $13,17 \pm 0,27^{b}$ & $\mathrm{P}<0.01$ \\
\hline & Epididimario & $0^{\mathrm{a}}$ & $15,53 \pm 3,24^{b}$ & $15,03 \pm 1,42^{b}$ & $14,90 \pm 2,87^{b}$ & $14,35 \pm 1,94^{b}$ & $13,20 \pm 2,15^{\mathrm{b}}$ & $\mathrm{P}<0.01$ \\
\hline $\mathrm{P}$ & & - & 0,45 & 0,36 & 0,34 & 0,57 & 0,99 & \\
\hline \multirow{2}{*}{$\begin{array}{l}\text { \% Unión espz } \\
\text { muertos }\end{array}$} & Eyaculado & $0^{\mathrm{a}}$ & $11,37 \pm 1,56^{\mathrm{b}}$ & $11,72 \pm 1,31^{\mathrm{b}}$ & $11,04 \pm 0,52^{\mathrm{b}}$ & $14,58 \pm 1,02^{b}$ & $11,73 \pm 0,19^{b}$ & $\mathrm{P}<0.01$ \\
\hline & Epididimario & $0^{\mathrm{a}}$ & $11,18 \pm 1,86^{\mathrm{b}}$ & $12,00 \pm 1,29^{b}$ & $13,08 \pm 2,41^{\mathrm{b}}$ & $12,42 \pm 1,78^{b}$ & $11,88 \pm 1,76^{\mathrm{b}}$ & $\mathrm{P}<0.01$ \\
\hline $\mathrm{P}$ & & - & 0,94 & 0,88 & 0,43 & 0,32 & 0,95 & \\
\hline \multirow{2}{*}{$\begin{array}{l}\text { \% Unión espz } \\
\text { vivos }\end{array}$} & Eyaculado & $0^{\mathrm{a}}$ & $1,70 \pm 0,39^{b}$ & $1,38 \pm 0,27^{b^{*}}$ & $0,90 \pm 0,24^{b}$ & $1,07 \pm 0,08^{b^{*}}$ & $1,43 \pm 0,09^{b}$ & $\mathrm{P}<0.01$ \\
\hline & Epididimario & $0^{\mathrm{a}}$ & $4,35 \pm 1,65^{b}$ & $3,03 \pm 0,42^{\mathrm{b}^{* *}}$ & $1,82 \pm 0,48^{a b}$ & $1,93 \pm 0,31^{\mathrm{b}^{* *}}$ & $1,32 \pm 0,43^{\mathrm{b}}$ & $\mathrm{P}<0.01$ \\
\hline $\mathrm{P}$ & & - & 0,09 & 0,01 & 0,12 & 0,02 & 0,85 & \\
\hline
\end{tabular}

** En la misma columna indican diferencias significativas $(\mathrm{P}<0,05)$ entre tipo de espermatozoides (eyaculados y epididimarios).

a, b En la misma fila indican diferencias significativas $(\mathrm{P}<0,05)$ asociados al tiempo de incubación $(0,15,30,60,90$ y 120 min $)$. 


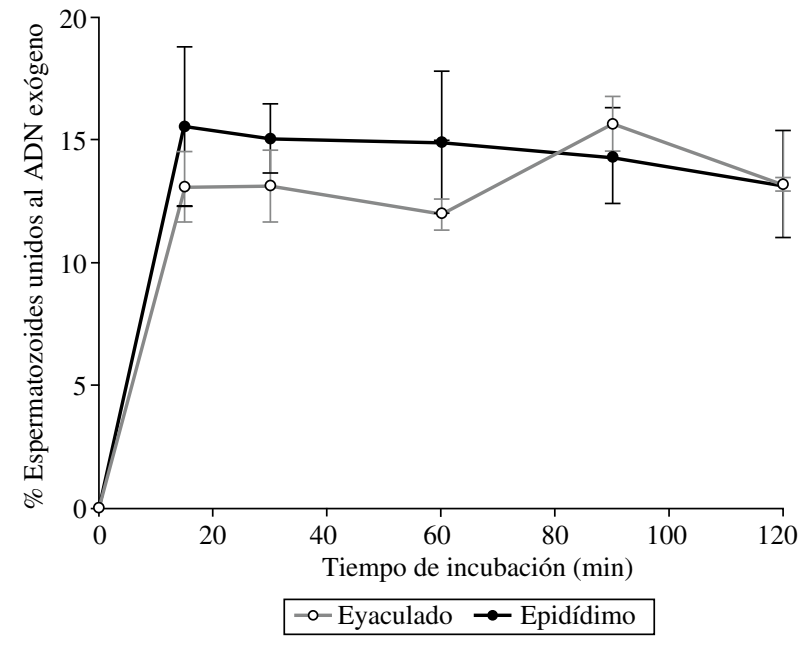

Figura 1. Cinética de unión entre el ADN exógeno y los espermatozoides eyaculados y epididimarios (unión total, tanto a espermatozoides muertos como vivos) medidos a diferentes tiempos a lo largo de 120 min de incubación, evaluados mediante el citómetro de flujo. Observamos que para ambos grupos en los primeros 15 min de incubación se produce el mayor porcentaje de unión.

Binding kinetic between spermatozoa (ejaculated vs epididymal) and exogenous DNA (total binding: sperm alive and dead) throughout 120 min of incubation evaluated by flow cytometry. Results showed that the main DNA binding to sperm was achieved as soon as $15 \mathrm{~min}$ of incubation in both groups.

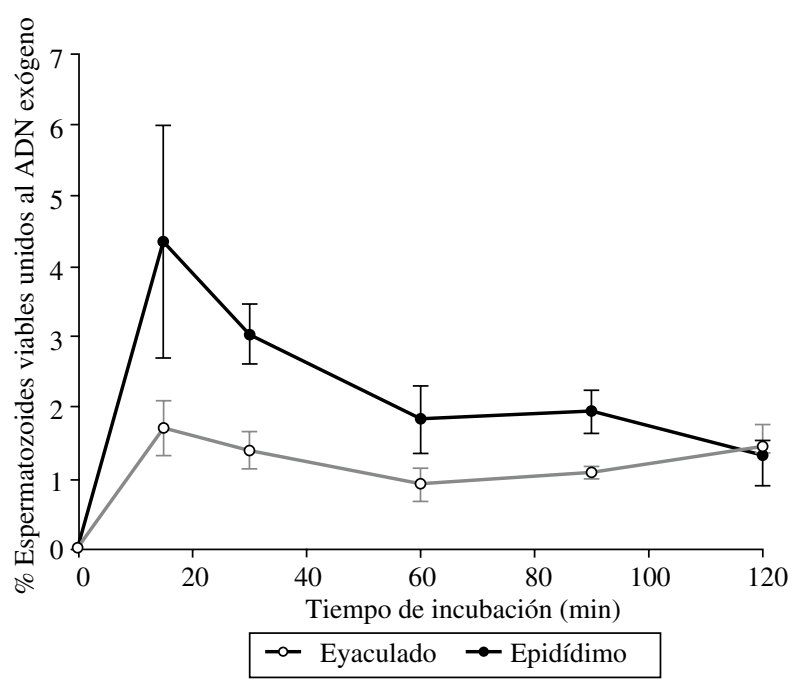

Figura 2. Cinética de unión entre el ADN exógeno y los espermatozoides viables de origen eyaculado y epididimario medidos a diferentes tiempos a lo largo de 120 min de incubación evaluados mediante el citométro de flujo. Observamos que en los primeros 30 min de incubación la unión a células vivas es mayor en los espermatozoides epididimarios.

Binding kinetic between alive spermatozoa (ejaculated vs epididymal) and exogenous DNA throughout $120 \mathrm{~min}$ of incubation evaluated by flow cytometry. Results showed that in the first 30 min of incubation the binding was higher in epididymal sperm than ejaculated.

Cuadro 2. Datos medios de unión (entre espermatozoides y ADN exógeno) y viabilidad a lo largo de 120 min de incubación (datos medios incluyendo las medidas en los diferentes tiempos de incubación: 0, 15, 30, 60, 90 y 120 min) para espermatozoides epididimarios y eyaculados sin plasma seminal.

Mean values (at different times of incubation: 0, 15, 30, 60, 90 and $120 \mathrm{~min}$ ) for DNA binding and viability of epididymal and ejaculated spermatozoa cultured for $120 \mathrm{~min}$.

\begin{tabular}{lcccc}
\hline Tipo espermatozoides & \% Espz muertos & \% Unión Total & \% Unión Espz muertos & \% Unión Espz vivos \\
\hline Epididimario & $14,64 \pm 0,94$ & $12,63 \pm 1,23$ & $10,53 \pm 1,01$ & $2,10 \pm 0,33^{\mathrm{a}}$ \\
Eyaculado & $13,42 \pm 0,61$ & $10,94 \pm 1,05$ & $9,89 \pm 0,97$ & $1,05 \pm 0,14^{\mathrm{b}}$ \\
$\mathrm{P}$ & 0,23 & 0,31 & 0,98 & $<0,01$ \\
\hline
\end{tabular}

a, b En la misma columna indican diferencias significativas $(\mathrm{P}<0,05)$

$9,89 \pm 0,97 \%, P=0,98)$. Sin embargo, detectamos un mayor porcentaje de células vivas con unión al ADN en los espermatozoides de origen epididimario $(2,10 \pm 0,33 \%$ vs $1,05 \pm 0,14 \%, \mathrm{P}<0,01)$ que en los eyaculados. Esto supone que mientras en los espermatozoides unidos a ADN el 9,97 $\pm 1,10 \%$ de ellos son viables, en el caso de los epididimarios aumenta significativamente $(\mathrm{P}<0,01)$ hasta el 15,43 $\pm 1,71 \%$ (cuadro 2 y figura 2 ).

En relación a la viabilidad espermática, evaluada con ioduro de propidio, y medida mediante el citómetro de flujo, observamos que para ambos casos (espermatozoides eyaculados y epididimarios) el porcentaje de células muertas es similar en los diferentes tiempos de incubación, siendo el porcentaje de células no viables más bajo al inicio de la medición (tiempo 0) (Eyaculado: 8,90 $\pm 1,32 \%$ vs Epididimario: 9,38 $\pm 1,76 \%$ ) (cuadro 1 y figura 3 ).

\section{DISCUSIÓN}

Desde que se redescubrió la SMGT hasta nuestros días se han publicado numerosos trabajos en relación a esta técnica de transgénesis, que demuestran el éxito en numerosas especies (Spadafora 1998, Smith y Spadafora 2005).

Si las células espermáticas pueden actuar como vectores de secuencias génicas exógenas, significa que el 


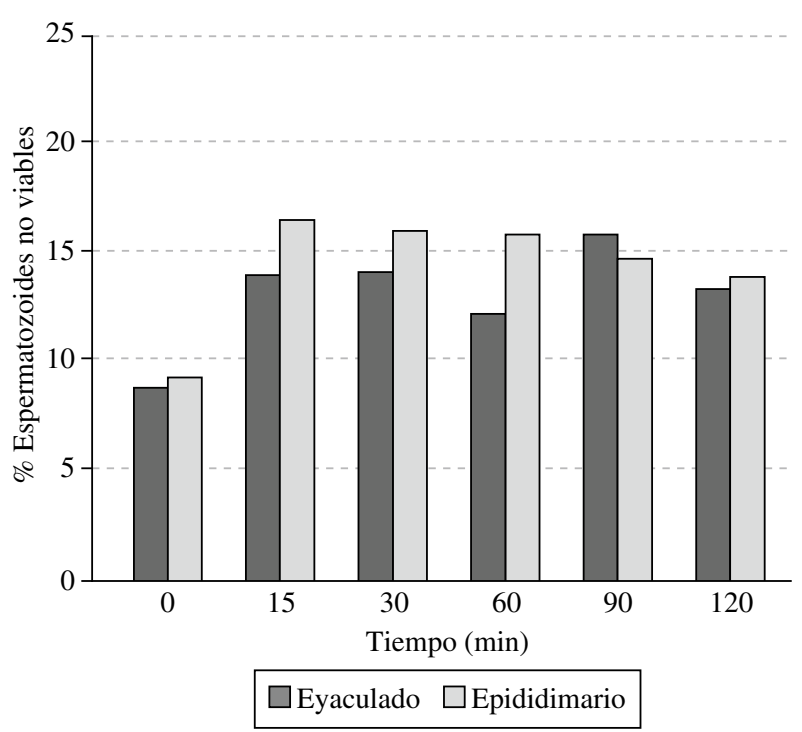

Figura 3. Espermatozoides no viables (teñidos con ioduro de propidio) de origen eyaculado y epididimario medidos mediante citometría de flujo en diferentes tiempos de incubación $(0,15$, 30, 60, 90 y $120 \mathrm{~min})$.

Ejaculated and epididymal dead spermatozoa (stained by propidium iodide) measured by flow cytometry throughout at different incubation times $0,15,30,60,90$ y $120 \mathrm{~min}$ ).

genoma de animales reproducidos sexualmente puede estar expuesto a la influencia de los genes foráneos que pueden transportarse unidos a los espermatozoides, con importantes implicaciones en los procesos evolutivos. De aquí procede el escepticismo generado por el método SMGT debido al caos evolutivo que supondría que las células espermáticas fueran capaces de actuar como vectores de ADN exógeno.

Dado que en los tractos reproductivos se puede encontrar ADN procedente de diversas células (bacterias, etc.), material subcelular y virus que pueden contener moléculas de ADN libre (originarias de la muerte celular natural), es por tanto razonable pensar que las células espermáticas son altamente resistentes a la hora de capturar dichas moléculas. Debido a las numerosas publicaciones relacionadas con la SMGT y el hecho de que ningún caos evolutivo al respecto se ha producido, cabe pensar que la naturaleza posee formidables barreras que eviten que el espermatozoide sea capaz de transferir ADN exógeno al nuevo embrión, aunque estas barreras no son absolutas ni infranqueables, debido a los resultados obtenidos con esta técnica. Entre las barreras que antagonizan la captación y el transporte del ADN exógeno podrían encontrarse la actividad enzimática en los espermatozoides, además de que el plasma seminal (PS) o componentes presentes en el mismo inhiban el proceso de unión. Los espermatozoides están sujetos a la interacción con las proteínas procedentes del epidídimo y del PS. Estas proteínas tienen como función estabilizar las membranas espermáticas frente a una prematura capacitación y una reacción acrosómica espontánea (Vadnais y Roberts 2006). Por lo tanto, el plasma seminal podría jugar un papel importante actuando como una barrera natural y protegiendo a los espermatozoides de intrusiones de moléculas exógenas que pudieran comprometer la integridad del espermatozoide y la identidad genética de la progenie. Indudablemente la membrana plasmática de los espermatozoides es uno de los obstáculos que previene la incorporación de ADN exógeno.

En los resultados obtenidos en nuestra investigación los espermatozoides epididimarios presentan una capacidad de unión similar que los eyaculados (a los que se ha eliminado el plasma seminal) tanto en el grado de unión al ADN como en la viabilidad a lo largo de la incubación. Únicamente detectamos un mayor porcentaje de unión del ADN a las células vivas en el grupo epididimario que es detectado por la alta sensibilidad y repetitividad que aporta la citometría de flujo (Gillan y col 2005). Sin embargo, entendemos que esa diferencia estadística (de un 1 a un 2\%) aun teniendo un escaso valor biológico podría ser objeto de un estudio más profundo que permitiera comprender el proceso de unión e interacción de la célula espermática y el ADN exógeno. La diferencia en el porcentaje de unión en espermatozoides vivos puede estar relacionada con diferentes patrones de capacitación que presentan los espermatozoides epididimarios (Matás y col 2007), habiendo autores que opinan que los espermatozoides procedentes de epidídimo se capacitan más fácilmente que los eyaculados (Yanagimachi 1994), por lo que según establecen Lavitrano y col (2003), que la unión se produce principalmente en estadios tempranos de capacitación, podría ser ésta una de las causas por las cuales los espermatozoides epididimarios se unen al ADN exógeno en los primeros minutos de incubación en un mayor porcentaje que los espermatozoides eyaculados.

Antes de la incubación con el plásmido EGFP el semen se centrifuga dos veces para eliminar el plasma seminal que inhibe la unión, por lo que una pérdida de la motilidad (Kang y col 2008) y por tanto de la viabilidad puede ser debida al efecto de la centrifugación. También se sugiere que los espermatozoides maduros contienen nucleasas inducidas por la interiorización del ADN exógeno que pueden dar lugar a la degradación del ADN cromosómico del espermatozoide y del ADN exógeno que ha sido unido (Maione y col 1997, Spadafora 1998, Szczygiel y col 2003). Además, el plasma seminal es la mayor fuente de protección contra agentes oxidativos del espermatozoide y la eliminación por tanto del plasma seminal aumenta la producción de agentes reactivos de oxígeno, resultando en un aumento en el daño del ADN y por tanto una disminución en la viabilidad espermática (Aitken y col 1988).

En cualquier caso, el hecho de poder obtener una eficiencia similar al utilizar los espermatozoides epididimarios que los eyaculados tras el tratamiento de eliminación del plasma seminal en la capacidad de interacción con el ADN 
pone de manifiesto que el proceso de eliminación de proteínas del plasma es efectivo. Además, podríamos utilizar en un futuro este tipo de espermatozoides epididimarios y congelarlos, y así poder usar el mismo macho en diversas experiencias sin que la variabilidad del verraco afecte a la repetitividad de los resultados (Rath y col 1997).

Por otro lado, en nuestras investigaciones se confirma el hecho de que la mayor parte de la unión de las moléculas de ADN y espermatozoides se produce en células muertas o con alteraciones graves de la membrana. La hipótesis más verosímil que explique este hecho es que la alteración o fractura de la membrana espermática favorezca la interacción con el ADN y permita fijarse a la región perinuclear. Pero también es posible que la unión al ADN induzca la alteración y muerte del espermatozoide por la activación de las endonucleasas. Cuando las nucleasas son activadas por la presencia del $\mathrm{ADN}$ exógeno, catalizan la degradación localizada del ADN cromosómico del espermatozoide. La degradación del ADN y la modulación de la actividad de las nucleasas nos recuerdan a la apoptosis asociada al ADN descrita en las células somáticas (Spadafora 1998) y consecuentemente llevan a la muerte celular (Maione y col 1997). La apoptosis de la célula espermática podría ser, por tanto, un mecanismo natural para prevenir la transmisión de ADN exógeno a la siguiente generación (Anzar y Buhr 2006).

Es la primera referencia desde nuestro conocimiento donde se evalúa la capacidad de unión de ADN exógeno a espermatozoides epididimarios mediante citometría de flujo, siendo una técnica que nos permite evaluar un gran número de células en un corto periodo de tiempo de una manera muy precisa y eficaz.

Con este estudio hemos demostrado que los espermatozoides libres de plasma seminal (tanto epididimarios como eyaculados) son capaces de interaccionar con el ADN exógeno, y por tanto se podría utilizar la técnica de SMGT combinada con técnicas de reproducción asistida como la ICSI con el fin de obtener embriones y lechones transgénicos (García-Vázquez 2007) como alternativa a la microinyección pronuclear, ya que la frecuencia de producción de animales transgénicos mediante SMGT se encuentra alrededor de 50-60\%, contrastando con la eficiencia de 0,5-4\% usando la microinyección (Niemann y Kues 2000), y produciendo un menor número de descendientes (entre 2 y 3 ) en comparación con la SMGT (entre 6 y 14). Sin embargo, se requiere investigar más sobre esta técnica para comprender el transporte del ADN exógeno en los espermatozoides en el tracto reproductivo in vivo, y habilidad para participar en el proceso de fecundación y cómo el ADN exógeno se introduce en los ovocitos.

\section{RESUMEN}

La transgénesis es una potente herramienta biotecnológica para la generación de animales modificados genéticamente con aplicaciones en diversas áreas como veterinaria, biomedicina y agricultura. En 1989 se describe un nuevo método para la producción de animales transgénicos, la transgénesis mediada por espermatozoides (SMGT). Este método está basado en la habilidad intrínseca de las células espermáticas para unir ADN exógeno y permitir su transferencia al interior de los ovocitos. El objetivo de este estudio fue comparar la capacidad de transferencia de ADN exógeno que presenta el espermatozoide eyaculado libre de plasma seminal vs epididimario, así como la viabilidad y cinética de unión mediante la citometría de flujo. Los resultados que obtuvimos mostraron que los espermatozoides epididimarios presentan una capacidad similar a los eyaculados y centrifugados tanto en el grado de unión al $\operatorname{ADN}(12,63 \pm 1,23 \%$ vs $10,94 \pm 1,05 \%, P=0,31)$ como en la viabilidad (espermatozoides no viables $14,64 \pm 0,94 \%$ vs $13,42 \pm 0,61 \%, \mathrm{P}=0,23$ ) a lo largo del tiempo de incubación. La mayor parte de dicha unión tiene lugar en los espermatozoides no viables para ambos tipos de espermatozoides $(10,53 \pm 1,01 \%$ vs $9,89 \pm 0,97 \%, P=0,98)$. En relación a la cinética de unión, observamos que para ambos grupos experimentales el mayor porcentaje de unión con el transgén ocurre en los primeros 15 minutos de coincubación, a partir del cual la unión se mantiene más o menos constante hasta los 120 minutos. Con este estudio hemos demostrado que tanto espermatozoides epididimarios como eyaculados son capaces de interactuar con el ADN exógeno, por lo que se podría utilizar la SMGT combinada con técnicas de reproducción asistida como la ICSI para la obtención de embriones y lechones transgénicos.

\section{AGRADECIMIENTOS}

Este trabajo ha sido subvencionado por los proyectos BIOCARM 10BIO2005/01-6463 y MEC-FEDER AGL2006-03495.

\section{REFERENCIAS}

Aitken RJ, JS Clarkson. 1988. Significance of reactive oxygen species and antioxidants in defining the efficacy of sperm preparation techniques. J Androl 9, 367-376.

Anzar M, MM Buhr. 2006. Spontaneous uptake of exogenous DNA by bull spermatozoa. Theriogenology 65, 683-690.

Bachiller D, K Schellander, J Peli, U Ruther. 1991. Liposome-mediated DNA uptake by sperm cells. Mol Reprod Dev 30, 194-200.

Birnstiel ML, M Busslinger. 1989. Dangerous liaisons: spermatozoa as natural vectors for foreign DNA? Cell 57, 701-702.

Brackett BG, W Boranska, W Sawicki, H Koprowiski. 1971. Uptake of heterologus genome by mammalian spermatozoa and its transfer to ova through fertilization. Proc Natl Acad Sci 68, 353-357.

Brinster RL, EP Sandgren, RR Behringer, RD Palmiter. 1989. No simple solution for making transgenic mice. Cell 59, 239-241.

Fainsold A, A Frumkin, Z Rangini, E Revel, S Yarus, A Benyehuda, Y Gruenbaum. 1990. Chicken homeogenes expressed during gastrulation and the generation of transgenic chicken. In: EMBO-EMBL Symp, Mol Biol Vertebrate Dev 31.

Gadea J, C Matás, X Lucas. 1998. Prediction of porcine semen fertility by homologous in vitro penetration (hIVP) assay. Anim Reprod Sci 54, 95-108.

Gandolfi F. 1998. Spermatozoa, DNA binding and transgenic animals. Transgenic Res 7, 147-155.

García-Vázquez F. 2007. Transgénesis mediada por espermatozoides en la especie porcina: factores que afectan a la eficiencia de la técnica. Tesis Doctoral, Facultad de Veterinaria, Universidad de Murcia, España.

Gillan L, G Evans, WM Maxwell. 2005. Flow cytometric evaluation of sperm parameters in relation to fertility potential. Theriogenology 63 , 445-457.

Gordon JW, FH Ruddle. 1981. Integration and stable germ line transmission of genes injected into mouse pronuclei. Science 214, 1244-1246.

Gutiérrez-Adán A, B Pintado. 2000. Effect of flanking matrix attachment regions on the expression of microinjected transgenes during 
preimplantation development of mouse embryos. Transgenic Res 9, 81-89.

Harrison RA, SE Vickers. 1990. Use of fluorescent probes to assess membrane integrity in mammalian spermatozoa. J Reprod Fertil 88, 343-352.

Hochi S, T Minomiya, A Mizuno, M Homma, A Yuchi. 1990. Fate of exogenous DNA carried into mouse eggs by spermatozoa. Anim Biotechnol 1, 25-30.

Jonak J. 2000. Sperm-mediated preparation of transgenic Xenopus laevis and transmission of transgenic DNA to the next generation. Mol Reprod Dev 56, 298-300.

Kang JH, H Hakimov, A Ruiz, RM Friendship, M Buhr, SP Golovan. 2008. The negative effects of exogenous DNA binding on porcine spermatozoa are caused by removal of seminal fluid. Theriogenology 70, 1288-1296.

King GJ, JW Macpherson. 1973. Fertility of beef cows treated during estrus with human chorionic gonadotrophin. Can Vet J 14, 221-222.

Kroll KL, E Amaya. 1996. Transgenic Xenopus embryos from sperm nuclear transplantations reveal FGF signaling requirements during gastrulation. Development 122, 3173-3183.

Kuznetsov AV, IV Kuznetsova. 1995. Binding of exogenous DNA pRK3lacZ by the rabbit spermatozoa, its transfer in the oocytes, and expression in the preimplantation embryos. Russian J Dev Biol 26, 300-309.

Lavitrano M, A Camaioni, VM Fazio, S Dolci, MG Farace, C Spadafora. 1989. Sperm cells as vectors for introducing foreign DNA into eggs: genetic transformation of mice. Cell 57, 717-723.

Lavitrano M, D French, M Zani, L Frati, C Spadafora. 1992. The interaction between exogenous DNA and sperm cells. Mol Reprod Dev 31, 161-169.

Lavitrano M, E Maione, E Forte, M Francolini, S Sperandio, R Testi, C Spadafora. 1997. The interaction of sperm cells with exogenous DNA: A role of CD4 and major histocompatibility complex class II molecules. Exp Cell Res 233, 56-62.

Lavitrano M, ML Bacci, M Forni, D Lazzereschi, C Di Stefano, D Fioretti, P Giancotti, G Marfe, L Pucci, L Renzi, H Wang, A Stoppacciaro, G Stassi, M Sargiacomo, P Sinibaldi, V Turchi, R Giovannoni, G Della Casa, E Seren, G Rossi. 2002. Efficient production by sperm-mediated gene transfer of human decay accelerating factor (hDAF) transgenic pigs for xenotransplantation. Proc Natl Acad Sci 99, 14230-14235.

Lavitrano M, M Forni, ML Bacci, C Di Stefano, V Varzi, H Wang, E Seren. 2003. Sperm mediated gene transfer in pig: Selection of donor boars and optimization of DNA uptake. Mol Reprod Dev 64, 284-291.

Maione B, C Pittoggi, L Achene, R Lorenzini, C Spadafora. 1997. Activation of endogenous nucleases in mature sperm cells upon interaction with exogenous DNA. DNA Cell Biol 16, 1087-1097.

Maione B, ML Lavitrano, C Spadafora, A Kiessling. 1998. Sperm-Mediated Gene Transfer in Mice. Mol Reprod Dev 50, 406-409.

Matás C, FA García-Vázquez, M Sansegundo, J Gadea P Coy, S Ruiz. 2007. Estudio de la capacitación espermática in vitro en espermatozoides eyaculados y epididimarios. ITEA información técnica económica agraria $28,30-32$.

Nagashima H, T Fujimura, Y Takahagi, M Kurome, N Wako, T Ochiai, R Esaki, K Kano, S Saito, M Okabe, H Murakami. 2003. Development of efficient strategies for the production of genetically modified pigs. Theriogenology 59, 95-106.
Niemann H, WA Kues. 2000. Transgenic livestock: premises and promises. Anim Reprod Sci 60-61, 277-293.

Niemann H, WA Kues. 2003. Application of transgenesis in livestock for agriculture and biomedicine. Anim Reprod Sci 79, 291-317.

Pérez A, R Solano, FO Castro, RL Lleonart, R de Armas, R Martinez, A Aguilar, L Herrera, J De la Fuente. 1991. Sperm cells mediated gene transfer in cattle. Biotecnol Aplicada 8, 90-94.

Rath D, H Niemann. 1997. In vitro fertilization of porcine oocytes with fresh and frozen-thawed ejaculated or frozen-thawed epididymal semen obtained from identical boars. Theriogenology 47, 785-793.

Rieth A, F Pothier, MA Sirard. 2000. Electroporation of bovine spermatozoa to carry DNA containing highly repetitive sequences into oocytes and detection of homologous recombination events. Mol Reprod Dev 57, 338-345.

Sato M, A Ishikawa, M Kimura. 2002. Direct injection of foreign DNA into mouse testis as a possible in vivo gene transfer system via epididymal spermatozoa. Mol Reprod Dev 61, 49-56.

Schellander K, J Peli, F Schomoll, G Brem. 1995. Artificial insemination in cattle with DNA-treated sperm. Anim Biotechnol 6, 41-50.

Sciamanna I, S Piccoli, L Barberi, G Zaccagnini, AR Magnano, R Giordano, P Campedelli, C Hodgson, R Lorenzini, C Spadafora. 2000. DNA dose and sequence dependence in sperm-mediated gene transfer. Mol Reprod Dev 56, 301-305.

Sin FYT, SP Walker, JE Symonds, UK Mukherjee, JG Khoo, IL Sin. 2000. Electroporation of salmon sperm for gene transfer: efficiency, reliability, and fate of transgene. Mol Reprod Dev 56, 285-288.

Smith K, C Spadafora. 2005. Sperm-mediated gene transfer: applications and implications. Bioessays 27, 551-562.

Spadafora C. 1998. Sperm cells and foreign DNA: a controversial relation. Bioessays 20, 955-964.

Sperandio S, V Lulli, ML Bacci, M Forni, B Maione, C Spadafora, M Lavitrano. 1996. Sperm mediated gene transfer in bovine and swine species. Anim Biotechnol 7, 59-77.

Szczygiel MA, S Moisyadi, WS Ward. 2003. Expression of foreign DNA is associated with paternal chromosome degradation in intracytoplasmic sperm injection-mediated transgenesis in the mouse. Biol Reprod 68, 1903-1910.

Vadnais ML, KP Roberts. 2006. Effects of seminal plasma on coolinginduced capacitative changes in boar sperm. $J$ Androl 28, 416-422.

Venugopal T, V Anathy, S Kirankumar, TJ Pandian. 2004. Growth enhancement and food conversion efficiency of transgenic fish Labeo rohita. J Exp Zoolog A Comp Exp Biol 301, 477-490.

Wang HJ, AX Lin, ZC Zhang, YF Chen. 2001. Expression of porcine growth hormone gene in transgenic rabbits as reported by green fluorescent protein. Anim Biotechnol 12, 101-110.

Yanagimachi R. 1994. Mammalian fertilization. In: Knobil E, JD Neill (eds). The Physiology of Reproduction. Raven Press, New York, USA, Pp 189-317.

Yang CC, HS Chang, CJ Lin, CC Hsu, JL Cheung, L Hwu, WTK Cheng. 2004. Cock spermatozoa serve as the gene vector for generation of transgenic chicken (Gallus gallus). Asian Austral J Anim Sci 17, 885-891.

Zani M, M Lavitrano, D French, V Lulli, B Maione, S Sperandio, C Spadafora. 1995. The mechanism of binding of exogenous DNA to sperm cells: factors controlling the DNA uptake. Exp Cell Res 217, 57-64. 